\title{
A Study on the Quality Criteria of Some Mandarin Varieties and Their Suitability for Juice Processing
}

\author{
Erdal Ağçam and Asiye Akyıldız \\ Department of Food Engineering, Çukurova University, 01330 Adana, Turkey \\ Correspondence should be addressed to Asiye Akyıldız; asiyel@cu.edu.tr
}

Received 15 May 2014; Revised 10 August 2014; Accepted 11 August 2014; Published 26 August 2014

Academic Editor: Soichiro Nakamura

Copyright ( 2014 E. Ağçam and A. Akyıldız. This is an open access article distributed under the Creative Commons Attribution License, which permits unrestricted use, distribution, and reproduction in any medium, provided the original work is properly cited.

\begin{abstract}
In this study, some composition properties of juices of different mandarin varieties (Robinson (R), Fremont (F), and Satsuma (S)) were determined before and after pasteurisation. $L^{*}, a^{*}, b^{*}$, and $C^{*}$ values of all varieties were increased after the pasteurisation process. Degradation of ascorbic acid was calculated as $2.20,16.86$, and $24.31 \%$ for R, F, and S samples, respectively, after pasteurisation. The highest total carotenoid and phenolic contents were determined in $S$ samples. In general, after the pasteurisation treatment, the total carotenoid content of juices was increased slightly, but total phenolic contents were dramatically decreased. The antioxidant activity of pasteurised samples was increased by approximately $6 \%$. The most abundant carotenoid and flavanone glycoside compound was shown to be $\beta$-cryptoxanthin and hesperidin, respectively, in all samples. The most popular fresh and pasteurised juice samples were made from the Robinson variety of mandarin with regard to taste, smell, and general impression.
\end{abstract}

\section{Introduction}

Citrus has long been one of the largest world crops and its juice is one of the most appreciated by consumers. One of the reasons for this is the high quality of their nutritional composition. Turkey is one of the major citrus-producing countries of the northern Mediterranean region, with a suitable climate and other ecological conditions and was the fifth largest world producer of mandarin (872,251 metric tons) in 2011 [1].

Citrus fruits and their derived products have a beneficial effect on human health. Citrus fruits are attractive because of their nutritional and antioxidant properties [2-5]; the prevention of diseases by nutrition is strongly supported [6], mainly due to the contribution of antioxidant compounds including vitamin $\mathrm{C}$, phenolic compounds, and carotenoids [5]. Dhuique-Mayer et al. [3] compared the influence of variety and species on the content of the main antioxidant microconstituents (flavonoids, carotenoids, and vitamin C) of different citrus fruits cultivated in the Mediterranean region.

The production of single-strength citrus juice is increasing. The composition of fresh citrus juice is adversely affected by industrial processing and/or storage conditions. Industrial processing involves a number of different stages that result in some alterations from the original composition of fresh citrus juice [7]. Pasteurisation is essential to improve the shelflife and safety of fruit juice. Pectin methyl esterase (PME) is an enzyme of major impact in citrus juice. If PME is not inactivated enough, this enzyme is caused losses in the natural cloud quality of citrus juices. PME is more thermally resistant than vegetative spoilage microorganisms; therefore, the target of pasteurisation of citrus juice is PME [8]. The delicate fresh composition of citrus juices is easily changed by pasteurisation, as the juice undergoes various compositional changes. Pasteurisation has negative impacts on the quality of mandarin juice, such as the loss of colour, flavour, nutritional value, and, as a result, taste [9].

Some investigators [10-13] have monitored a gradual decrease in certain aromas and an increase in undesirable components during processing and storage. However, limited references have been found for the effects of pasteurisation on the chemical composition of different mandarin cultivar juices. In order for processors to better understand the changes that take place during the thermal processing of mandarin juices, quantitative information on the components present in both fresh and pasteurised mandarin juice is 
needed. Such information will provide a list of varieties that are more appropriate for the production of juice.

The main objective of this study was to compare the chemical composition of three mandarin cultivars (Robinson, Fremont, and Satsuma) that are currently grown in Turkey and to determine the chemical changes that occur as a result of pasteurisation.

\section{Materials and Methods}

2.1. Juice Processing. Robinson (R) (Citrus reticulata, hybrid of Clementine $\times$ Orlando), Fremont $(\mathrm{F})$ (Citrus reticulata, hybrid of Clementine $\times$ Ponkan), and Satsuma (S) (Citrus unshiu) mandarin varieties grown in the Cukurova Region of Turkey were used in this study. After being washed, mandarins were cut into two halves and pressed using a benchscale automatic squeezing machine (CANCAN, Turkey). Mandarin juices were passed through $1 \mathrm{~mm}$ stainless steel sieves to remove seeds and coarse pulp. Juice was immediately processed by heat pasteurisation. The study was carried out with three replications.

2.2. Heat Pasteurisation. The bench-scale system designed in the Department of Food Engineering of Cukurova University (Adana, Turkey) was used for heat pasteurisation applications [14]. As a result of the preliminary experiments, heat was applied at $95^{\circ} \mathrm{C}$ for $15 \mathrm{~s}$ for pasteurisation. Heat-pasteurised samples were placed in amber coloured bottles for further analyses. Pasteurised samples were called Robinson (RP), Fremont (FP), and Satsuma (SP) in future analyses.

2.3. General Properties of Mandarin Juices. Total acidity and dry matter of juice samples were carried out according to AOAC [15]. Brix and $\mathrm{pH}$ of mandarin juices were analysed with an Abbe refractometer (Carl Zeiss, Jena, Germany) and WTW pH-meter (Weilheim, Germany), respectively.

2.4. Colour Measurement. Colour ( $\left.\mathrm{CIE} L^{*}, a^{*}, b^{*}\right)$ analysis was conducted by the Colour Flex HunterLab instrument. $50 \mathrm{~mL}$ of juice was transferred to the $20 \mathrm{~mm}$ Glass Optical Cell Light Path and analysed. The results were given according to the CIELAB colour system. In this system, $L^{*}$ defines lightness (0: black; 100: white), $a^{*}$ denotes the red/green value $\left((+)\right.$ : red; (-): green), and $b^{*}$ denotes the yellow/blue value $((+)$ : yellow; $(-)$ : blue). In addition, the following formulas were used for the calculations of Hue ${ }^{*}, C^{*}$ and $\Delta E^{*}$ colour values:

$$
\begin{gathered}
\mathrm{Hue}^{*}=\arctan \left(\frac{b^{*}}{a^{*}}\right), \\
C^{*}=\sqrt{\left(a^{*}\right)^{2}+\left(b^{*}\right)^{2}}, \\
\Delta E^{*}=\sqrt{\left(\Delta L^{*}\right)^{2}+\left(\Delta a^{*}\right)^{2}+\left(\Delta b^{*}\right)^{2}} .
\end{gathered}
$$

2.5. Determination of Browning Index. $5 \mathrm{~mL}$ of each variety of mandarin juice was mixed with $5 \mathrm{~mL}$ ethyl alcohol (95\%) in teflon tubes and then centrifuged $(4000 \mathrm{rpm}, 10 \mathrm{~min}$, at $\left.4^{\circ} \mathrm{C}\right)$. The supernatant was passed through a $0.45 \mu \mathrm{m}$ teflon membrane filter and the absorbance of the supernatant was obtained at $420 \mathrm{~nm}$ in a spectrophotometer (Perkin Elmer Lambda 25-UV/VIS, USA) [16].

2.6. Determination of Hydroxymethylfurfural (HMF). HMF extractions of samples were carried out according to the method reported by Gökmen and Acar [17]. The best chromatographic conditions were determined as a result of preliminary experiments as follows: $20 \mu \mathrm{L}$ of supernatant was injected into the $\mathrm{C} 18 \mathrm{ACE}(4.6 \times 250 \mathrm{~mm})$ column; the column was maintained at $30^{\circ} \mathrm{C}$ with a flow rate of $0.5 \mathrm{~mL} / \mathrm{min}$; and the photodiode array detector was set at $285 \mathrm{~nm}$. Methanol/water/acetic acid (20/79/1, v/v/v) was used as mobile phases.

2.7. Antioxidant Activity. The antioxidant activity of the mandarin juices was evaluated using the $\mathrm{DPPH}^{*}$ free radicalscavenging method. The $\mathrm{DPPH}^{*}$ free radical-scavenging activity measurements were carried out according to the procedure of Klimczak et al. [18] with some modifications. $5 \mathrm{~mL}$ of mandarin juices was mixed with $5 \mathrm{~mL}$ of methyl alcohol $(80 \%)$ in teflon tubes and then centrifuged (4000 rpm, $10 \mathrm{~min}$, at $4^{\circ} \mathrm{C}$ ). Briefly, $0.1 \mathrm{~mL}$ of supernatant was added to $2.46 \mathrm{~mL}$ of 1,1-diphenyl-2-picrylhydrazyl radical $\left(\mathrm{DPPH}^{*} ; 0.025 \mathrm{gL}^{-1}\right.$ in $80 \%$ methyl alcohol) and mixed by vortex. After incubation for $10 \mathrm{~min}$ in the dark, the absorbance of the samples was measured at $515 \mathrm{~nm}$ using the spectrophotometer. The antioxidant activity was expressed as the percentage decline of the absorbance as follows:

$$
\text { Antioxidant activity }(\%)=\left(\frac{A_{\text {control }}-A_{\text {sample }}}{A_{\text {control }}}\right) \times 100 \text {, }
$$

where $A_{\text {control }}$ is the absorbance of the control and $A_{\text {sample }}$ is the absorbance of the sample.

2.8. Determination of PME Activity. For the measurement of PME activity, $10 \mathrm{~mL}$ of mandarin juice was mixed with $20 \mathrm{~mL}$ of $1 \%$ pectin-salt substrate $(0.1 \mathrm{M} \mathrm{NaCl})$ and incubated at $30^{\circ} \mathrm{C}$. The solution was adjusted to $\mathrm{pH} 7.0$ with $2.0 \mathrm{~N} \mathrm{NaOH}$, and the $\mathrm{pH}$ of the solution was readjusted to 7.7 with $0.05 \mathrm{~N} \mathrm{NaOH}$. After the $\mathrm{pH}$ reached $7.7,0.10 \mathrm{~mL}$ of $0.05 \mathrm{~N} \mathrm{NaOH}$ was added. Time was measured $\left(t^{\prime}\right)$ until the $\mathrm{pH}$ returned to 7.7. PME activity (\%) was calculated as follows [19]:

$$
\begin{gathered}
\text { PME Activity }(A)=\frac{\left(0.05 \mathrm{~N}_{\mathrm{NaOH}}\right)\left(0.10 \mathrm{~mL}_{\mathrm{NaOH}}\right)}{\left(t^{\prime}\right)\left(10 \mathrm{~mL}_{\text {sample }}\right)}, \\
\text { Residual PME Activity }(\%)=\left(\frac{A_{t}}{A_{0}}\right) 100,
\end{gathered}
$$

where $t^{\prime}$ is time in $\min , A_{0}$ is initial PME activity, and $A_{t}$ is PME activity after pasteurisation.

2.9. Determination of Total Carotenoid Content. Total carotenoid determination was carried out according to the 
previously described method of Lee and Castle [20] with some modifications. $5 \mathrm{~mL}$ of juice and $10 \mathrm{~mL}$ of hexane solution (hexane/methanol/acetone, 50/25/25, v/v with $0.1 \%$ BHT) were mixed and then centrifuged for $10 \mathrm{~min}$ $4000 \mathrm{rpm}$ at $4^{\circ} \mathrm{C}$. The supernatant phase was used to measure the absorbance $(450 \mathrm{~nm})$ using a spectrophotometer. Total carotenoids were calculated using the extinction coefficient of $\beta$-carotene $\left(E^{1 / 2}=2505\right)$.

2.10. Determination of Carotenoid Compounds. Pigment extraction from juices and saponification procedures were carried out according to the previously reported method of Meléndez-Martínez et al. [21].

HPLC analyses were carried out by means of a Shimadzu LC-20AT (Japan) system, consisting of a quaternary pump, a column temperature control oven (CTO-10AS), an autosampler unit (SIL-20A), a degasser module (DGU$20 \mathrm{~A}_{5}$ ), and a photodiode array detector (SPD-M20A). $50 \mu \mathrm{L}$ of supernatant was injected into the C30 ProntoSIL $(5.0 \mu \mathrm{m}$, $4.6 \times 250 \mathrm{~mm}$ ) column. The column was kept at $20^{\circ} \mathrm{C}$ and the flow rate was $1 \mathrm{~mL} / \mathrm{min}$. The photodiode array detector was set to $450 \mathrm{~nm}$. Methanol (A), methyl-tert-butyl ether (B) and ultrapure water $(\mathrm{C})$ were used as mobile phases. According to the preliminary experiments, the best gradient elution was as follows: 0 min: $90 \% \mathrm{~A}+5 \% \mathrm{~B}+5 \% \mathrm{C} ; 5 \mathrm{~min}$ : $95 \% \mathrm{~A}+5 \%$ B; 40 min: $75 \% \mathrm{~A}+25 \%$ B; 55 min: $55 \% \mathrm{~A}+45 \% \mathrm{~B}$; 60 min: $90 \% A+5 \% B+5 \%$ C; 65 min: $90 \% A+5 \% B+5 \%$ C.

The carotenoid compounds were identified by comparing their UV-visible spectra and retention times with that of corresponding standards. Quantification of carotenoid compounds was carried out at $450 \mathrm{~nm}$ using external standard method.

2.11. Determination of Ascorbic Acid Content. Ascorbic acid determination was performed using the HPLC method and extraction procedure according to Lee and Coates [22]. The HPLC column was maintained at $25^{\circ} \mathrm{C}$ and the flow rate was $0.5 \mathrm{~mL} / \mathrm{min}$. $10 \mu \mathrm{L}$ of supernatant was injected into the C18 XTerra (Waters, $4.6 \times 250 \mathrm{~mm}$ ) column. The photodiode array detector was set at $244 \mathrm{~nm}$, and $2 \% \mathrm{KH}_{2} \mathrm{PO}_{4}$ (pH 2.4) was used as the mobile phase.

2.12. Determination of Total Phenolic Content. The total phenolic compounds in the study samples were measured using the Folin-Ciocalteu method with some modifications [23]. For the measurement of phenolic compounds, $5 \mathrm{~mL}$ of mandarin juice was mixed with $5 \mathrm{~mL}$ of $80 \%$ methanol in teflon tubes and the tubes were then centrifuged at $4000 \mathrm{rpm}$ for 20 minutes at $4^{\circ} \mathrm{C}$ (Heraeus Bofuge Primo R, Germany). For the analysis, $100 \mu \mathrm{L}$ of appropriately diluted sample (various concentrations) or standard solution was mixed with $100 \mu \mathrm{L}$ Folin-Ciocalteu reagent and $3000 \mu \mathrm{L}$ deionised water and mixed thoroughly. After incubation for $10 \mathrm{~min}$ at room temperature, $100 \mu \mathrm{L}$ of $20 \% \mathrm{Na}_{2} \mathrm{CO}_{3}$ solution was added followed by immediate mixing; the solution was further incubated at room temperature for $2 \mathrm{~h}$ in the dark. The absorbance of the mixture was then measured at $765 \mathrm{~nm}$ using a spectrophotometer (Perkin Elmer Lambda
25-UV/VIS, USA). Gallic acid was used as the standard and the total phenolic compounds of the samples were expressed in milligrams per $\mathrm{L}$ of gallic acid equivalents (mgGAE/L).

2.13. Determination of Phenolic Compounds. For the measurement of phenolic compounds, $5 \mathrm{~mL}$ of mandarin juice was mixed with $10 \mathrm{~mL}$ of $80 \%$ methanol in the teflon tubes and sonicated (Bandelin Sonerex, Germany) at room temperature $\left(\sim 25^{\circ} \mathrm{C}\right)$ for 15 minutes. Then, tubes were centrifuged at $4000 \mathrm{rpm}$ for 10 minutes at $4^{\circ} \mathrm{C}$ (Heraeus Bofuge Primo $\mathrm{R}$, Germany). Finally, the supernatant was passed through a $0.45 \mu \mathrm{m}$ teflon membrane filter and injected into the HPLC instrument [14].

HPLC analyses were carried out by means of a Shimadzu LC-20AT (Japan) system, consisting of a quaternary pump, a column temperature control oven (CTO-10AS), an autosampler unit (SIL-20A), a degasser module (DGU$20 \mathrm{~A}_{5}$ ), and a photodiode array detector (SPD-M20A). $20 \mu \mathrm{L}$ of supernatant was injected into the C18 XTerra (Waters, $4.6 \times$ $250 \mathrm{~mm}$ ) column. The column was kept at $30^{\circ} \mathrm{C}$ and the flow rate was $0.8 \mathrm{~mL} / \mathrm{min}$. The photodiode array detector was set to 280 and $320 \mathrm{~nm}$. 2\% formic acid (A) and $100 \%$ ACN (B) were used as mobile phases. According to the preliminary experiments, the best gradient elution was as follows: $0 \mathrm{~min}$ : $100 \% \mathrm{~A} ; 10 \mathrm{~min}: 95 \% \mathrm{~A}+5 \% \mathrm{~B} ; 25 \mathrm{~min}: 90 \% \mathrm{~A}+10 \%$; $55 \mathrm{~min}$ : $80 \% \mathrm{~A}+20 \% \mathrm{~B} ; 70 \mathrm{~min}: 55 \% \mathrm{~A}+45 \% \mathrm{~B} ; 90 \mathrm{~min}: 100 \% \mathrm{~B}$; 95 min: $100 \% \mathrm{~A}$.

The phenolic compounds were identified by comparing their UV-visible spectra and retention times with that of corresponding standards. Quantification of phenolic compounds was carried out at 280 and $320 \mathrm{~nm}$ using external standard method. Calibration curves were obtained using the commercial standards of the concentrations normally present in mandarin, obtaining regression coefficients $\left(R^{2}\right)$ above 0.997 in all cases.

2.14. Sensory Analysis. Juices were evaluated using a graphic scale test. The panel was composed of eighteen assessors from our department. Five sensory parameters (colour, turbidity, taste, smell, and general impression) were established for mandarin juices, each of which was given a score out of ten.

2.15. Statistical Analysis. The software SPSS 20 for Windows (SPSS Inc., Chicago, IL, USA) was used for analysis of variance (ANOVA) and Duncan's multiple comparison test in order to determine significant differences between the treatments. Each experiment was repeated at least three times.

\section{Results and Discussion}

3.1. General Properties of Mandarin Juices. The general properties of the mandarin juices and the effects of pasteurisation on these properties are shown in Table 1. Brix of mandarin juices changed between $12.47 \pm 0.06-13.60 \pm 0.26$, with the biggest value found for the F sample. Total dry matter of fresh and pasteurised mandarin juices ranged between $12.95 \pm$ $0.37-14.16 \pm 0.01 \%$ and there was no difference between 
TABLE 1: General properties and PME activities of mandarin juices.

\begin{tabular}{|c|c|c|c|c|c|c|}
\hline & $\mathrm{R}$ & $\mathrm{RP}$ & $\mathrm{F}$ & FP & S & SP \\
\hline Brix $^{\circ}$ & $12.65 \pm 0.13^{c}$ & $12.47 \pm 0.06^{\mathrm{c}}$ & $13.60 \pm 0.26^{\mathrm{a}}$ & $13.50 \pm 0.25^{\mathrm{a}}$ & $13.03 \pm 0.12^{\mathrm{b}}$ & $12.52 \pm 0.03^{\mathrm{c}}$ \\
\hline Total dry matter (\%) & $12.95 \pm 0.37^{\mathrm{b}}$ & $13.25 \pm 0.06^{\mathrm{b}}$ & $13.86 \pm 0.28^{\mathrm{a}}$ & $14.16 \pm 0.01^{\mathrm{a}}$ & $13.08 \pm 0.15^{\mathrm{b}}$ & $12.97 \pm 0.01^{\mathrm{b}}$ \\
\hline $\mathrm{pH}$ & $3.19 \pm 0.01^{b c}$ & $3.22 \pm 0.05^{\mathrm{b}}$ & $3.17 \pm 0.01^{c}$ & $3.27 \pm 0.01^{\mathrm{a}}$ & $3.12 \pm 0.01^{\mathrm{d}}$ & $3.18 \pm 0.01^{\mathrm{c}}$ \\
\hline Total acidity $(\mathrm{g} / 100 \mathrm{~mL})$ & $1.04 \pm 0.01^{\mathrm{de}}$ & $1.02 \pm 0.01^{\mathrm{e}}$ & $1.11 \pm 0.02^{\mathrm{c}}$ & $1.07 \pm 0.01^{\mathrm{cd}}$ & $1.53 \pm 0.04^{\mathrm{a}}$ & $1.46 \pm 0.03^{\mathrm{b}}$ \\
\hline PME activity (\%) & $100^{\mathrm{a}}$ & $5.59 \pm 0.28^{c}$ & $100^{\mathrm{a}}$ & $13.87 \pm 0.69^{b}$ & $100^{\mathrm{a}}$ & $14.26 \pm 0.60^{\mathrm{b}}$ \\
\hline Yield (\%) & $36.67 \pm 0.25^{\mathrm{b}}$ & - & $43.48 \pm 0.29^{\mathrm{a}}$ & - & $35.75 \pm 0.14^{\mathrm{b}}$ & - \\
\hline
\end{tabular}

Superscript lowercase letter show the significant differences with each row $(P<0.05) . \pm$ standard deviation.

$\mathrm{R}$ and RP: fresh and pasteurized juice of Robinson; respectively. F and FP: fresh and pasteurized juice of Fremont; respectively. S and SP: fresh and pasteurized juice of Satsuma; respectively.

TABLE 2: Color properties and HMF concentration of mandarin juices.

\begin{tabular}{|c|c|c|c|c|c|c|}
\hline & $\mathrm{R}$ & $\mathrm{RP}$ & $\mathrm{F}$ & FP & $\mathrm{S}$ & SP \\
\hline$L^{*}$ & $30.43 \pm 1.48^{\mathrm{b}}$ & $33.08 \pm 0.25^{\mathrm{a}}$ & $28.43 \pm 0.47^{\mathrm{c}}$ & $31.59 \pm 0.22^{\mathrm{b}}$ & $31.48 \pm 0.34^{\mathrm{b}}$ & $33.46 \pm 0.17^{\mathrm{a}}$ \\
\hline$a^{*}$ & $-1.73 \pm 0.33^{\mathrm{e}}$ & $-1.11 \pm 0.09^{\mathrm{d}}$ & $-0.54 \pm 0.09^{c}$ & $-1.02 \pm 0.04^{\mathrm{d}}$ & $3.59 \pm 0.28^{\mathrm{b}}$ & $4.83 \pm 0.11^{\mathrm{a}}$ \\
\hline$b^{*}$ & $16.65 \pm 1.14^{\mathrm{bc}}$ & $16.80 \pm 0.22^{\mathrm{bc}}$ & $16.17 \pm 0.77^{\mathrm{c}}$ & $17.45 \pm 0.21^{\mathrm{b}}$ & $18.92 \pm 0.24^{\mathrm{a}}$ & $19.81 \pm 0.21^{\mathrm{a}}$ \\
\hline Hue $^{*}$ & $96.00 \pm 1.57^{\mathrm{a}}$ & $93.79 \pm 0.27^{\mathrm{b}}$ & $91.94 \pm 0.39^{c}$ & $93.34 \pm 0.10^{\mathrm{b}}$ & $79.26 \pm 0.69^{\mathrm{d}}$ & $76.31 \pm 0.39^{\mathrm{e}}$ \\
\hline$C^{*}$ & $16.75 \pm 1.10^{\mathrm{cd}}$ & $16.84 \pm 0.22^{\mathrm{cd}}$ & $16.18 \pm 0.77^{\mathrm{d}}$ & $17.48 \pm 0.21^{\mathrm{c}}$ & $19.26 \pm 0.28^{\mathrm{b}}$ & $20.39 \pm 0.19^{\mathrm{a}}$ \\
\hline$\Delta E^{*}$ & \multicolumn{2}{|c|}{$2.84 \pm 1.31^{\mathrm{a}}$} & \multicolumn{2}{|c|}{$3.53 \pm 0.20^{\mathrm{a}}$} & \multicolumn{2}{|c|}{$2.50 \pm 0.29^{\mathrm{a}}$} \\
\hline Browning index $(\mathrm{abs})^{* *}$ & $0.16 \pm 0.00^{\mathrm{bc}}$ & $0.14 \pm 0.01^{\mathrm{c}}$ & $0.16 \pm 0.01^{\mathrm{bc}}$ & $0.14 \pm 0.03^{\mathrm{c}}$ & $0.22 \pm 0.00^{\mathrm{a}}$ & $0.18 \pm 0.01^{\mathrm{b}}$ \\
\hline HMF (ppb) & n.d. & $7.13 \pm 0.27^{\mathrm{b}}$ & n.d. & $4.62 \pm 0.84^{\mathrm{c}}$ & n.d. & $10.69 \pm 0.46^{\mathrm{a}}$ \\
\hline
\end{tabular}

"Superscript lowercase letter show the significant differences with each row $(P<0.01) . \pm$ standard deviation. ${ }^{* *}$ Absorbance.

$\mathrm{R}$ and RP: fresh and pasteurized juice of Robinson; respectively. F and FP: fresh and pasteurized juice of Fremont; respectively. S and SP: fresh and pasteurized juice of Satsuma; respectively.

fresh and pasteurised samples $(P>0.05)$. The $\mathrm{pH}$ and total acidity of juice samples were between $3.12 \pm 0.01-3.27 \pm 0.01$ and $1.02 \pm 0.01-1.53 \pm 0.04 \mathrm{~g} / 100 \mathrm{~mL}$, respectively. After the pasteurisation process, the acidity of juices was found to be significantly decreased $(P<0.05)$. Finally, the highest yield, which is a very important factor for citrus juicing industries, was calculated for the Fremont $(43.48 \pm 0.29 \%)$ variety.

\subsection{Colour Properties and HMF Content of Mandarin Juices.}

Colour values of fresh and pasteurised juices are given in Table 2. $L^{*}$ values were determined to be $30.43,28.43$, and 31.48 for R, F, and $\mathrm{S}$, respectively. $L^{*}$ values of pasteurised juices were increased after the pasteurisation process $(P<$ 0.05 ) and found to be $33.08,31.59$, and 33.46 for RP, FP, and SP, respectively. The $a^{*}$ and $b^{*}$ values of mandarin juices ranged between $-1.73-4.83$ and 16.17-19.81, respectively. After the pasteurisation process, $a^{*}$ and $b^{*}$ values of all varieties were increased, as was the colour value of $L^{*}(P<0.05)$.

Hue ${ }^{*}, C^{*}$, and $\Delta E^{*}$ colour values were derived using the values of basic CIELAB colour parameter $\left(L^{*}, a^{*}, b^{*}\right)$. The first of these Hue* values is described, with basic colours (red, yellow, green, and blue) being closer to the colour of the object. The $C^{*}$ value defines the saturation of the colour object. The point of intersection with $\mathrm{Hue}^{*}$ and $C^{*}$ values is known as the colour of the object (Figure 1). Finally, $\Delta E^{*}$ value is given for the total colour difference after any operation.

Hue $^{*}$ values were calculated as $96.00 \pm 1.57,93.79 \pm 0.27$, $91.94 \pm 0.39,93.34 \pm 0.10,79.26 \pm 0.69$, and $76.31 \pm 0.39$

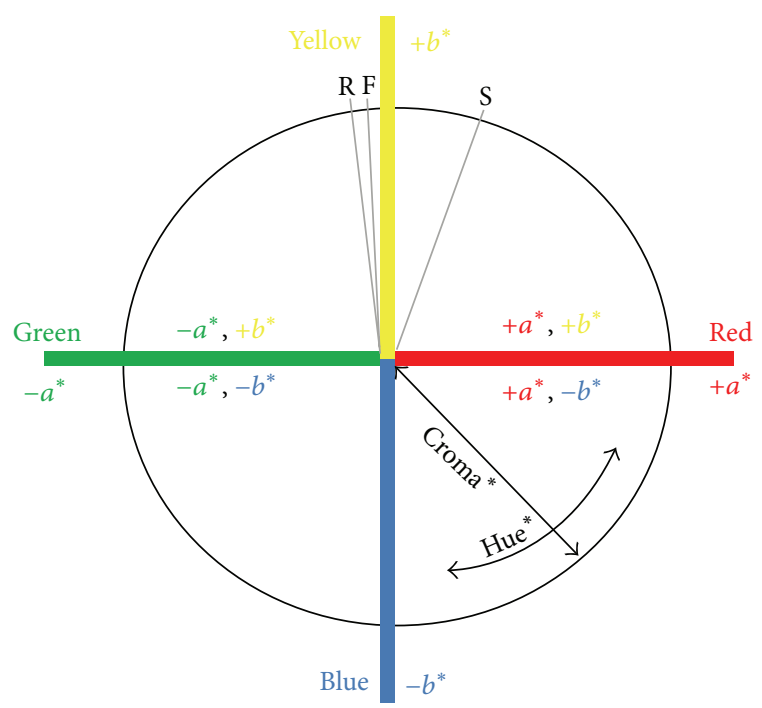

FIGURE 1: Graph of color according to CIELAB scale (pasteurized juice of Robinson (R), Fremont (F), and Satsuma (S)).

for R, RP, F, FP, S, and SP samples, respectively. According to the results, after pasteurisation, the Hue ${ }^{*}$ value of Fremont was increased, but the Hue ${ }^{*}$ values of Robinson and Satsuma were decreased $(P<0.05)$. $C^{*}$ values ranged between $16.18 \pm 0.77-20.39 \pm 0.19$ for mandarin juices and were higher for $\mathrm{S}$ than for $\mathrm{R}$ and $\mathrm{F}$ samples. In addition, this value was slightly increased after pasteurisation treatment for all 
TABLE 3: Bioactive compound concentrations and antioxidant activities of mandarin juices.

\begin{tabular}{|c|c|c|c|c|c|c|}
\hline & $\mathrm{R}$ & $\mathrm{RP}$ & $\mathrm{F}$ & FP & $\mathrm{S}$ & SP \\
\hline Ascorbic Acid (mg/L) & $546.82 \pm 5.30^{\mathrm{a}}$ & $534.81 \pm 7.89^{\mathrm{a}}$ & $362.72 \pm 13.02^{\mathrm{b}}$ & $301.55 \pm 45.45^{\mathrm{c}}$ & $282.25 \pm 26.41^{\mathrm{c}}$ & $213.63 \pm 8.92^{\mathrm{d}}$ \\
\hline Total carotenoid (mg/L) & $17.20 \pm 0.41^{\mathrm{e}}$ & $17.36 \pm 0.84^{\mathrm{e}}$ & $20.06 \pm 0.90^{\mathrm{d}}$ & $22.43 \pm 0.95^{\mathrm{c}}$ & $30.32 \pm 1.76^{\mathrm{b}}$ & $33.11 \pm 1.74^{\mathrm{a}}$ \\
\hline Total phenolic (mg/L) & $316.65 \pm 13.98^{\mathrm{ab}}$ & $291.10 \pm 20.36^{\mathrm{b}}$ & $298.43 \pm 26.02^{\mathrm{b}}$ & $237.60 \pm 14.51^{\mathrm{c}}$ & $336.23 \pm 8.39^{\mathrm{a}}$ & $260.17 \pm 11.06^{\mathrm{c}}$ \\
\hline Antioxidant activity (\%) & $77.69 \pm 0.73^{c}$ & $84.24 \pm 0.53^{\mathrm{a}}$ & $78.25 \pm 0.40^{\mathrm{bc}}$ & $84.19 \pm 0.82^{\mathrm{a}}$ & $79.11 \pm 0.59^{\mathrm{b}}$ & $85.13 \pm 0.38^{\mathrm{a}}$ \\
\hline \multicolumn{7}{|c|}{ Carotenoid compounds (mg/L) } \\
\hline$\beta$-cryptoxanthin & $6.29 \pm 1.21^{\mathrm{c}}$ & $6.65 \pm 0.88^{c}$ & $8.99 \pm 0.78^{\mathrm{b}}$ & $9.72 \pm 1.73^{\mathrm{b}}$ & $19.38 \pm 1.00^{\mathrm{a}}$ & $21.04 \pm 1.40^{\mathrm{a}}$ \\
\hline$\alpha$-caroten & $0.05 \pm 0.02^{\mathrm{b}}$ & $0.05 \pm 0.01^{\mathrm{b}}$ & $0.16 \pm 0.04^{\mathrm{a}}$ & $0.16 \pm 0.01^{\mathrm{a}}$ & $0.13 \pm 0.03^{\mathrm{a}}$ & $0.14 \pm 0.01^{\mathrm{a}}$ \\
\hline$\beta$-caroten & $0.35 \pm 0.05^{\mathrm{c}}$ & $0.35 \pm 0.06^{c}$ & $0.62 \pm 0.11^{\mathrm{ab}}$ & $0.72 \pm 0.15^{\mathrm{a}}$ & $0.48 \pm 0.07^{\mathrm{bc}}$ & $0.52 \pm 0.07^{\mathrm{bc}}$ \\
\hline lutein & $0.19 \pm 0.05^{\mathrm{c}}$ & $0.22 \pm 0.05^{\mathrm{bc}}$ & $0.45 \pm 0.03^{\mathrm{b}}$ & $0.40 \pm 0.02^{\mathrm{bc}}$ & $0.37 \pm 0.12^{\mathrm{bc}}$ & $0.82 \pm 0.28^{\mathrm{a}}$ \\
\hline zeaxanthin & $0.29 \pm 0.12^{\mathrm{bc}}$ & $0.33 \pm 0.06^{\mathrm{bc}}$ & $0.22 \pm 0.01^{\mathrm{c}}$ & $0.28 \pm 0.03^{b c}$ & $0.47 \pm 0.14^{\mathrm{b}}$ & $0.87 \pm 0.23^{\mathrm{a}}$ \\
\hline \multicolumn{7}{|c|}{ Phenolic compounds (mg/L) } \\
\hline gallic acid & $1.73 \pm 0.14^{\mathrm{a}}$ & $1.84 \pm 0.14^{\mathrm{a}}$ & $0.09 \pm 0.01^{\mathrm{c}}$ & $0.47 \pm 0.60^{\mathrm{cb}}$ & $0.75 \pm 0.04^{\mathrm{b}}$ & $0.92 \pm 0.21^{\mathrm{b}}$ \\
\hline vanillic acid & $2.11 \pm 0.16^{\mathrm{c}}$ & $1.80 \pm 0.03^{\mathrm{c}}$ & $3.12 \pm 0.25^{\mathrm{ab}}$ & $3.22 \pm 0.14^{\mathrm{ab}}$ & $2.97 \pm 0.64^{\mathrm{b}}$ & $3.74 \pm 0.53^{\mathrm{a}}$ \\
\hline chlorojenic acid & $3.26 \pm 0.13^{c}$ & $3.31 \pm 0.05^{\mathrm{c}}$ & $5.32 \pm 0.34^{\mathrm{b}}$ & $4.79 \pm 0.29^{\mathrm{b}}$ & $7.89 \pm 1.43^{\mathrm{a}}$ & $7.72 \pm 0.48^{\mathrm{a}}$ \\
\hline caffeic acid & $1.13 \pm 0.16^{\mathrm{b}}$ & $1.04 \pm 0.01^{\mathrm{b}}$ & $1.49 \pm 0.11^{\mathrm{b}}$ & $1.56 \pm 0.02^{\mathrm{b}}$ & $4.43 \pm 0.76^{\mathrm{a}}$ & $4.27 \pm 0.26^{\mathrm{a}}$ \\
\hline $\mathrm{PAEE}^{* *}$ & $4.18 \pm 0.39^{c}$ & $4.32 \pm 0.07^{\mathrm{bc}}$ & $4.72 \pm 0.48^{\mathrm{b}}$ & $6.58 \pm 0.28^{\mathrm{a}}$ & $0.26 \pm 0.03^{\mathrm{d}}$ & $0.42 \pm 0.06^{\mathrm{d}}$ \\
\hline$p$-cumaric acid & $0.69 \pm 0.53^{\mathrm{ab}}$ & $0.21 \pm 0.08^{\mathrm{b}}$ & $0.70 \pm 0.40^{\mathrm{ab}}$ & $0.23 \pm 0.24^{\mathrm{b}}$ & $1.29 \pm 0.39^{\mathrm{a}}$ & $0.66 \pm 0.04^{\mathrm{b}}$ \\
\hline syringic acid & $1.24 \pm 0.85^{\mathrm{bc}}$ & $0.14 \pm 0.01^{\mathrm{c}}$ & $2.69 \pm 0.19^{\mathrm{ab}}$ & $1.71 \pm 1.21^{\mathrm{ab}}$ & $2.88 \pm 0.50^{\mathrm{a}}$ & $1.78 \pm 1.26^{\mathrm{ab}}$ \\
\hline sinapic acid & $0.12 \pm 0.08^{\mathrm{c}}$ & $0.00 \pm 0.00^{\mathrm{d}}$ & $0.29 \pm 0.02^{\mathrm{b}}$ & $0.37 \pm 0.03^{\mathrm{a}}$ & $0.14 \pm 0.03^{c}$ & $0.10 \pm 0.02^{c}$ \\
\hline$o$-cumaric acid & $0.34 \pm 0.06^{\mathrm{b}}$ & $0.28 \pm 0.05^{\mathrm{ab}}$ & $0.18 \pm 0.05^{\mathrm{b}}$ & $0.24 \pm 0.02^{\mathrm{ab}}$ & $0.63 \pm 0.14^{\mathrm{a}}$ & $0.55 \pm 0.07^{\mathrm{a}}$ \\
\hline ferrulic acid & \multicolumn{2}{|c|}{ nd } & \multicolumn{2}{|c|}{ nd } & \multicolumn{2}{|c|}{ nd } \\
\hline hesperidin & $208.45 \pm 4.35^{\mathrm{b}}$ & $126.48 \pm 6.11^{\mathrm{c}}$ & $226.23 \pm 20.86^{\mathrm{b}}$ & $149.78 \pm 3.29^{c}$ & $282.95 \pm 28.93^{\mathrm{a}}$ & $217.73 \pm 5.97^{b}$ \\
\hline neohesperidin & $0.40 \pm 0.14^{\mathrm{ab}}$ & $0.00 \pm 0.00^{\mathrm{b}}$ & $0.36 \pm 0.06^{\mathrm{ab}}$ & $1.59 \pm 1.73^{\mathrm{a}}$ & $0.45 \pm 0.09^{\mathrm{ab}}$ & $1.76 \pm 0.94^{\mathrm{a}}$ \\
\hline eriocitrin & \multicolumn{2}{|c|}{ nd } & \multicolumn{2}{|c|}{ nd } & \multicolumn{2}{|c|}{ nd } \\
\hline neoeriocitrin & \multicolumn{2}{|c|}{ nd } & \multicolumn{2}{|c|}{ nd } & \multicolumn{2}{|c|}{ nd } \\
\hline naringenin & $0.58 \pm 0.03^{\mathrm{a}}$ & $0.43 \pm 0.10^{\mathrm{b}}$ & $0.61 \pm 0.02^{\mathrm{a}}$ & $0.60 \pm 0.00^{\mathrm{a}}$ & $0.64 \pm 0.03^{\mathrm{a}}$ & $0.64 \pm 0.02^{\mathrm{a}}$ \\
\hline naringin & \multicolumn{2}{|c|}{ nd } & \multicolumn{2}{|c|}{ nd } & \multicolumn{2}{|c|}{ nd } \\
\hline quercetin & \multicolumn{2}{|c|}{ nd } & \multicolumn{2}{|c|}{ nd } & \multicolumn{2}{|c|}{ nd } \\
\hline isoquercetin & $0.73 \pm 0.07^{\mathrm{b}}$ & $0.69 \pm 0.00^{\mathrm{b}}$ & $0.87 \pm 0.4^{\mathrm{a}}$ & $0.91 \pm 0.02^{\mathrm{a}}$ & $0.67 \pm 0.02^{\mathrm{b}}$ & $0.67 \pm 0.01^{b}$ \\
\hline rutin & \multicolumn{2}{|c|}{ nd } & $3.57 \pm 2.56^{\mathrm{b}}$ & $5.64 \pm 0.26^{\mathrm{a}}$ & \multicolumn{2}{|c|}{ nd } \\
\hline luteolin & $0.10 \pm 0.02^{\mathrm{b}}$ & $0.13 \pm 0.07^{\mathrm{b}}$ & $0.18 \pm 0.04^{\mathrm{b}}$ & $0.12 \pm 0.04^{\mathrm{b}}$ & $0.38 \pm 0.08^{\mathrm{a}}$ & $0.38 \pm 0.03^{\mathrm{a}}$ \\
\hline kamferol & $2.42 \pm 0.46^{\mathrm{a}}$ & $2.90 \pm 1.17^{\mathrm{a}}$ & $0.22 \pm 0.00^{\mathrm{b}}$ & $0.40 \pm 0.01^{\mathrm{b}}$ & $0.64 \pm 0.42^{\mathrm{b}}$ & $0.16 \pm 0.03^{\mathrm{b}}$ \\
\hline apijenin & \multicolumn{2}{|c|}{ nd } & \multicolumn{2}{|c|}{ nd } & \multicolumn{2}{|c|}{ nd } \\
\hline
\end{tabular}

Superscript lowercase letter show the significant differences with each row $(P<0.05) . \pm$ Standard deviation. ${ }^{* *}$ Protocatechuic acid ethyl ester. R and RP: fresh and pasteurized juice of Robinson; respectively. F and FP: fresh and pasteurized juice of Fremont; respectively. S and SP: fresh and pasteurized juice of Satsuma; respectively.

varieties $(P<0.05) . \Delta E^{*}$ values of samples ranged between $2.50 \pm 0.29-3.53 \pm 0.20$ after the pasteurisation treatment and the highest value was calculated for the Fremont variety $(P>0.05)$.

Browning indexes of samples were determined as an absorbance between $0.14 \pm 0.01-0.22 \pm 0.00$ and were decreased in pasteurised juices of all varieties $(P<0.05)$. HMF was not detected in fresh mandarin juices, but HMF concentrations of RP, FP, and SP were found to be $7.13 \pm$ $0.27,4.62 \pm 0.84$, and $10.69 \pm 0.46 \mathrm{ppb}$, respectively, after pasteurisation treatment.

3.3. Bioactive Compounds and Antioxidant Activities of Mandarin Juices. Bioactive compound concentrations and antioxidant activities of mandarin juices are given in Table 3. Ascorbic acid concentrations of mandarin juices ranged between $213.63 \pm 8.92-546.82 \pm 5.30 \mathrm{mg} / \mathrm{L}$, with the highest concentration observed in $\mathrm{R}$ samples $(P<0.05)$. After pasteurisation, ascorbic acid degradation was calculated as $2.20,16.86$, and $24.31 \%$ for RP, FP, and SP samples, respectively. Total carotenoid and phenolic contents of juices ranged between $17.20 \pm 0.41-33.11 \pm 1.74$ and $237.60 \pm 14.51-336.23 \pm$ $8.39 \mathrm{mg} / \mathrm{L}$, respectively. The highest total carotenoid and phenolic contents were determined in $\mathrm{S}$ samples $(P<$ 0.05). In general, after the pasteurisation treatment, the total carotenoid content of juices was increased slightly, but the total phenolic contents decreased dramatically. Hayat et al. [24] stated that the total phenolic acid content in mandarin pomace was decreased with increasing microwave power 
TABLE 4: Sensory analyses results of mandarin juices.

\begin{tabular}{|c|c|c|c|c|c|c|}
\hline & $\mathrm{R}$ & $\mathrm{RP}$ & $\mathrm{F}$ & FP & S & SP \\
\hline Color & $8.67 \pm 0.60^{\mathrm{a}}$ & $8.74 \pm 0.73^{\mathrm{a}}$ & $8.92 \pm 0.56^{\mathrm{a}}$ & $8.90 \pm 0.44^{\mathrm{a}}$ & $8.75 \pm 0.54^{\mathrm{a}}$ & $8.96 \pm 0.33^{\mathrm{a}}$ \\
\hline Turbidity & $8.39 \pm 0.64^{\mathrm{a}}$ & $8.91 \pm 0.33^{\mathrm{a}}$ & $8.95 \pm 0.71^{\mathrm{a}}$ & $8.80 \pm 0.36^{\mathrm{a}}$ & $8.62 \pm 0.45^{\mathrm{a}}$ & $8.47 \pm 0.57^{\mathrm{a}}$ \\
\hline Taste & $8.31 \pm 0.60^{\mathrm{ab}}$ & $7.37 \pm 0.27^{\mathrm{b}}$ & $8.53 \pm 0.31^{\mathrm{a}}$ & $5.53 \pm 0.73^{\mathrm{c}}$ & $8.09 \pm 0.26^{\mathrm{ab}}$ & $5.47 \pm 0.70^{\mathrm{C}}$ \\
\hline Smell & $8.55 \pm 0.50^{\mathrm{a}}$ & $5.95 \pm 0.51^{b}$ & $8.67 \pm 0.19^{\mathrm{a}}$ & $5.38 \pm 0.78^{b}$ & $8.73 \pm 0.29^{\mathrm{a}}$ & $5.72 \pm 0.12^{b}$ \\
\hline General impression & $8.99 \pm 0.28^{\mathrm{a}}$ & $7.78 \pm 0.56^{\mathrm{b}}$ & $8.59 \pm 0.57^{\mathrm{a}}$ & $6.58 \pm 0.39^{c}$ & $8.34 \pm 0.24^{\mathrm{ab}}$ & $5.28 \pm 0.41^{\mathrm{c}}$ \\
\hline
\end{tabular}

Superscript lowercase letter show the significant differences with each row $(P<0.05) . \pm$ standard deviation.

R and RP: fresh and pasteurized juice of Robinson; respectively. F and FP: fresh and pasteurized juice of Fremont; respectively. S and SP: fresh and pasteurized juice of Satsuma; respectively.

and treatment time. $\mathrm{Xu}$ et al. [25] reported that the free fraction of phenolic increased, whereas the ester, glycoside, and ester-bound fractions decreased after heat treatment. Moreover, there was a decrease of total phenolic acid content after heat treatment and the content of four flavanone glycosides (narirutin, naringin, hesperidin, and neohesperidin) declined with heating time and temperature.

According to the results of mandarin juices, it was found that these juices contain a high concentration of bioactive compounds (ascorbic acid, phenolic, and carotenoid), and antioxidant activities were determined to be high $(78.25 \pm$ $0.40-85.13 \pm 0.38 \%)$, as expected. Data show that pasteurisation treatment causes an increase in antioxidant activity, with an increase of approximately $6 \%(P<0.05)$.

$\mathrm{Xu}$ et al. [25] assumed that many antioxidant phenolic compounds in plants are usually presented as the covalently-bound form; therefore, some processing methods were employed to liberate them in order to enhance their antioxidant capacity. Jeong et al. [26] reported that heat treatment may liberate some low molecular weight phenolic compounds and increase the antioxidant capacity of citrus peel as a result. Hayat et al. [24] expressed that, after microwave treatment, the free fraction of phenolic acids increased, whereas the bound fractions decreased and antioxidant activity was increased. The increase in the antioxidant capacities of citrus pomaces was due, at least in part, to the increased phenolic content in the free fraction. Free phenolic compounds have been shown to have greater antioxidant effects than bound forms [27].

Carotenoid Compounds of Mandarin Juices. Carotenoid compounds of different mandarin juice samples are given in Table 3 . The most abundant carotenoid compound was found to be $\beta$-cryptoxanthin in all samples; this compound was higher than others in the Satsuma samples $(P<0.05)$. After pasteurisation treatments, differences between samples were not found to be important for $\beta$-cryptoxanthin, $\alpha$-carotene, and $\beta$-carotene but were important for zeaxanthin and lutein $(P<0.05)$.

Dhuique-Mayer et al. [28] reported that the main provitamin A carotenoids were not significantly affected during conventional thermal processing of citrus juice. These results agree with previously reported studies [29-32]. In these studies, losses of $\beta$-carotene or $\beta$-cryptoxanthin were very low during pasteurisation or the thermal concentration of different citrus juices. Sánchez-Moreno et al. [33] reported that cases of thermal treated orange juice $\left(90^{\circ} \mathrm{C}\right.$ for $\left.1 \mathrm{~min}\right)$ led to an increase in $\beta$-cryptoxanthin (19.19\%) and zeaxanthin $(37.49 \%)$ and to a decrease in lutein $(23.10 \%)$, whereas no changes were found in the extraction of $\beta$-cryptoxanthin or hydrocarbon carotenoids.

Phenolic Compounds of Mandarin Juices. Phenolic compounds of different mandarin juice samples are given in Table 3. As can be seen, nine phenolic acids (gallic acid, vanillic acid, chlorojenic acid, caffeic acid, protocatechuic acid ethyl ester (PAEE), $p$-cumaric acid, syringic acid, sinapic acid,and $o$-cumaric acid) were detected in the mandarin juice samples. Ferrulic acid was not detected in any of the samples. The most abundant phenolic acid was determined as PAEE $(4.18 \mathrm{mg} / \mathrm{L})$ in the Robinson variety and chlorogenic acid in Fremont $(5.32 \mathrm{mg} / \mathrm{L})$ and Satsuma $(7.89 \mathrm{mg} / \mathrm{L})$ varieties. In addition, six flavonoids (hesperidin, neohesperidin, naringenin, isoquercetin, luteolin, and kamferol) were detected in mandarin juices, but eriocitrin, neoeriocitrin, naringin, quercetin and apijenin were not detected in all mandarin varieties. Also, rutin was detected only for the Satsuma variety. Our results indicate that the most abundant flavanone glycoside identified in mandarin juice was hesperidin, but hesperidin concentrations were detected for R $(208.45 \mathrm{mg} / \mathrm{L})$, F $(226.23 \mathrm{mg} / \mathrm{L})$ and $\mathrm{S}(282.95 \mathrm{mg} / \mathrm{L})$. Naringin, hesperidin and neohesperidin are flavanone glycosides that are known to accumulate specifically in citrus species. They have different sugar moieties which influence taste; naringin and neohesperidin are neohesperidosides with a bitter taste due to the sugar neohesperidose, while the sugar rutinose causes hesperidin to have a neutral taste $[34,35]$.

Hesperidin concentrations of fresh mandarin juices were decreased dramatically after pasteurisation treatments $(P<$ 0.05). The amount of this compound was decreased for Robinson 39.33\%, Fremont 33.79\%, and Satsuma 23.05\% after pasteurisation treatments. Conversely, Dhuique-Mayer et al. [28] reported that hesperidin concentration was not significantly decreased during thermal treatments (losses $<2 \%$, at $90^{\circ} \mathrm{C}$ after $240 \mathrm{~min}$ ) in orange juice. The same results were in agreement with those of Sánchez-Moreno et al. [33], who stated that pasteurisation did not modify hesperidin content. In our samples, hesperidin was decreased following pasteurisation of mandarin juices.

3.4. Sensory Properties of Mandarin Juices. Sensory properties of mandarin juices are given in Table 4. Colour and 
turbidity properties of juice samples ranged between 8.678.94 and 8.39-8.95, respectively. After pasteurisation treatment, the colour of samples scored higher than fresh samples, but differences between juice samples were not important for colour. Also, there was no difference between turbidity properties of samples. The best scores for taste and smell were obtained from fresh juices, but the highest scores (7.37 and 5.95) after pasteurisation treatment were found for the $\mathrm{RP}$ sample. The general impression is a sensory property which describes the appreciation of a product; therefore, this property is very important for food producers. The general impression of fresh mandarin juices scored between 8.34-8.99. After pasteurisation, this value was significantly decreased $(P<0.05)$. The general impression of RP, FP and SP samples scored 7.78, 6.58 and 5.28, respectively. As a result, the most well-liked fresh and pasteurised juice samples were from the Robinson variety of mandarin.

\section{Conclusions}

After the pasteurisation process, $L^{*}, a^{*}, b^{*}$ and $C^{*}$ values of all varieties were increased. The Hue* value of Fremont (F) was increased but was decreased for Robinson (R) and Satsuma (S). The highest $\Delta E^{*}$ value of samples was calculated for the Fremont variety. Ascorbic acid concentration was determined to be highest for the Robinson variety and degradation was calculated as $2.20,16.86$, and $24.31 \%$ for samples of R, F, and S, respectively, after pasteurisation. The highest total carotenoid and phenolic contents were determined in $\mathrm{S}$ samples. In general, after the pasteurisation treatment, the total carotenoid content of juices was slightly increased, but total phenolic contents were dramatically decreased. Pasteurisation treatment caused an increase in antioxidant activity. The most abundant carotenoid compound was $\beta$ cryptoxanthin in all samples; nine phenolic acids and six flavonoids were detected in the mandarin juice samples. Hesperidin was detected at the highest concentration in all mandarin juices, but the hesperidin concentration of samples was decreased after the pasteurisation treatment. In sensory evaluation, colours of pasteurised samples scored higher than fresh samples. The most well-liked fresh and pasteurised juice samples were those of the Robinson variety of mandarin with regard to taste, smell and general impression. As a result, these varieties of mandarin are suitable for the fruit juice processing industry and have rich bioactive components which are important for human health. Also, by blending mandarin juices, richer bioactive contents and products with high consumer appreciation will be obtained.

\section{Conflict of Interests}

The authors declare that there is no conflict of interests regarding the publication of this paper.

\section{Acknowledgment}

This study was supported by Research Project Units of Çukurova University (Project no. ZF2007BAP45).

\section{References}

[1] FAO, “FAOSTAT: Statistical Database FAO Rome," 2013, http:// faostat.fao.org/.

[2] A. del Caro, A. Piga, V. Vacca, and M. Agabbio, "Changes of flavonoids, vitamin $\mathrm{C}$ and antioxidant capacity in minimally processed citrus segments and juices during storage," Food Chemistry, vol. 84, no. 1, pp. 99-105, 2004.

[3] C. Dhuique-Mayer, C. Caris-Veyrat, P. Ollitrault, F. Curk, and M. Amiot, "Varietal and interspecific influence on micronutrient contents in citrus from the mediterranean area," Journal of Agricultural and Food Chemistry, vol. 53, no. 6, pp. 2140-2145, 2005.

[4] T. Wu, Y. Guan, and J. Ye, "Determination of flavonoids and ascorbic acid in grapefruit peel and juice by capillary electrophoresis with electrochemical detection," Food Chemistry, vol. 100, no. 4, pp. 1573-1579, 2007.

[5] A. Cano, A. Medina, and A. Bermejo, "Bioactive compounds in different citrus varieties: discrimination among cultivars," Journal of Food Composition and Analysis, vol. 21, no. 5, pp. 377381, 2008.

[6] M. A. Anagnostopoulou, P. Kefalas, E. Kokkalou, A. N. Assimopoulou, and V. P. Papageorgiou, "Analysis of antioxidant compounds in sweet orange peel by HPLC-diode array detection-electrospray ionization mass spectrometry," Biomedical Chromatography, vol. 19, no. 2, pp. 138-148, 2005.

[7] M. J. Jordán, K. L. Goodner, and J. Laencina, "Deaeration and pasteurization effects on the orange juice aromatic fraction," LWT_Food Science and Technology, vol. 36, no. 4, pp. 391-396, 2003.

[8] C. S. Chen and M. C. Wu, "Kinetic models for thermal inactivation of multiple pectinesterases in citrus juices," Journal of Food Science, vol. 63, no. 5, pp. 747-750, 1998.

[9] A. Espachs-Barroso, A. van Loey, M. Hendrickx, and O. MartínBelloso, "Inactivation of plant pectin methylesterase by thermal or high intensity pulsed electric field treatments," Innovative Food Science and Emerging Technologies, vol. 7, no. 1-2, pp. 4048, 2006.

[10] P. Schreier and H. Idstein, "Advances in the instrumental analysis of food flavours," Zeitschrift für Lebensmittel-Untersuchung und-Forschung, vol. 180, no. 1, pp. 1-14, 1985.

[11] M. O. Nisperos-Carriedo and P. E. Shaw, "Comparison of volatile flavor components in fresh and processed orange juices," Journal of Agricultural and Food Chemistry, vol. 38, no. 4, pp. 1048-1052, 1990.

[12] P. J. Fellers and R. D. Carter, "Effect of thermal processing and storage of chilled orange juice on flavor quality," Fruit Processing, vol. 3, no. 12, pp. 436-441, 1993.

[13] M. G. Moshonas, P. E. Shaw, and B. S. Buslig, "Retention of fresh orange juice flavor and aroma in an aqueous distillate from Valencia orange juice," Journal of Food Quality, vol. 16, pp. 101$108,1993$.

[14] E. Ağçam, A. Akyıldız, and G. A. Evrendilek, "Comparison of phenolic compounds of orange juice processed by pulsed electric fields (PEF) and conventional thermal pasteurisation," Food Chemistry, vol. 143, pp. 354-361, 2014.

[15] AOAC, Official Method of Analysis of the Association of Official Analytical Chemistry, AOAC, Arlington, Va, USA, 15th edition, 1990.

[16] S. Meydav, I. Saguy, and I. J. Kopelman, "Browning determination in citrus products," Journal of Agricultural and Food Chemistry, vol. 25, no. 3, pp. 602-604, 1977. 
[17] V. Gökmen and J. Acar, "Rapid reversed-phase liquid chromatographic determination of patulin in apple juice," Journal of Chromatography A, vol. 730, no. 1-2, pp. 53-58, 1996.

[18] I. Klimczak, M. Małecka, M. Szlachta, and A. GliszczyńskaŚwigło, "Effect of storage on the content of polyphenols, vitamin $\mathrm{C}$ and the antioxidant activity of orange juices," Journal of Food Composition and Analysis, vol. 20, no. 3-4, pp. 313-322, 2007.

[19] D. A. Kimball, "Juice cloud," in Citrus Processing: Quality Control and Technology, pp. 117-125, Van Nostrand Reinhold, New York, NY, USA, 1991.

[20] H. S. Lee and W. S. Castle, "Seasonal changes of carotenoid pigments and color in Hamlin, Earlygold, and Budd Blood orange juices," Journal of Agricultural and Food Chemistry, vol. 49, no. 2, pp. 877-882, 2001.

[21] A. J. Meléndez-Martínez, I. S. Vicario, and F. J. Heredia, "Carotenoids, color, and ascorbic acid content of a novel frozen-marketed orange juice," Journal of Agricultural and Food Chemistry, vol. 55, no. 4, pp. 1347-1355, 2007.

[22] H. S. Lee and G. A. Coates, "Vitamin C in frozen, fresh squeezed, unpasteurized, polyethylene-bottled orange juice: a storage study," Food Chemistry, vol. 65, no. 2, pp. 165-168, 1999.

[23] P. Abdullakasim, S. Songchitsomboon, M. Techagumpuch, N. Balee, P. Swatsitang, and P. Sungpuag, "Antioxidant capacity, total phenolics and sugar content of selected thai health beverages," International Journal of Food Sciences and Nutrition, vol. 58, no. 1, pp. 77-85, 2007.

[24] K. Hayat, X. Zhang, U. Farooq et al., "Effect of microwave treatment on phenolic content and antioxidant activity of citrus mandarin pomace," Food Chemistry, vol. 123, no. 2, pp. 423-429, 2010.

[25] G. Xu, X. Ye, J. Chen, and D. Liu, "Effect of heat treatment on the phenolic compounds and antioxidant capacity of citrus peel extract," Journal of Agricultural and Food Chemistry, vol. 55, no. 2, pp. 330-335, 2007.

[26] S. Jeong, S. Kim, D. Kim et al., "Effect of heat treatment on the antioxidant activity of extracts from citrus peels," Journal of Agricultural and Food Chemistry, vol. 52, no. 11, pp. 3389-3393, 2004.

[27] Y. Niwa, T. Kanoh, T. Kasama, and M. Negishi, "Activation of antioxidant activity in natural medicinal products by heating, brewing and lipophilization. A new drug delivery system," Drugs under Experimental and Clinical Research, vol. 14, no. 5, pp. 361-372, 1988.

[28] C. Dhuique-Mayer, M. Tbatou, M. Carail, C. Caris-Veyrat, M. Dornier, and M. J. Amiot, "Thermal degradation of antioxidant micronutrients in Citrus juice: kinetics and newly formed compounds," Journal of Agricultural and Food Chemistry, vol. 55, no. 10, pp. 4209-4216, 2007.

[29] H. S. Lee and G. A. Coates, "Thermal pasteurization effects on color of red grapefruit juices," Journal of Food Science, vol. 64, no. 4, pp. 663-666, 1999.

[30] H. S. Lee and G. A. Coates, "Effect of thermal pasteurization on Valencia orange juice color and pigments," LWT_Food Science and Technology, vol. 36, no. 1, pp. 153-156, 2003.

[31] J. J. T. Gama and C. M. Sylos, "Major carotenoid composition of Brazilian Valencia orange juice: identification and quantification by HPLC," Food Research International, vol. 38, no. 8-9, pp. 899-903, 2005.

[32] C. Cortés, F. Torregrosa, M. J. Esteve, and A. Frígola, "Carotenoid profile modification during refrigerated storage in untreated and pasteurized orange juice and orange juice treated with high-intensity pulsed electric fields," Journal of Agricultural and Food Chemistry, vol. 54, no. 17, pp. 6247-6254, 2006.

[33] C. Sánchez-Moreno, L. Plaza, P. Elez-Martínez, B. De Ancos, O. Martín-Belloso, and M. P. Cano, "Impact of high pressure and pulsed electric fields on bioactive compounds and antioxidant activity of orange juice in comparison with traditional thermal processing," Journal of Agricultural and Food Chemistry, vol. 53, no. 11, pp. 4403-4409, 2005.

[34] J. J. Peterson, J. T. Dwyer, G. R. Beecher et al., "Flavanones in oranges, tangerines (mandarins), tangors, and tangelos: a compilation and review of the data from the analytical literature," Journal of Food Composition and Analysis, vol. 19, pp. S66-S73, 2006.

[35] I. Moulehi, S. Bourgou, I. Ourghemmi, and M. S. Tounsi, "Industrial crops and products variety and ripening impact on phenolic composition and antioxidant activity of mandarin (Citrus reticulate Blanco) and bitter orange (Citrus aurantium L.) seeds extracts," Industrial Crops and Products, vol. 39, pp. 7480, 2012. 

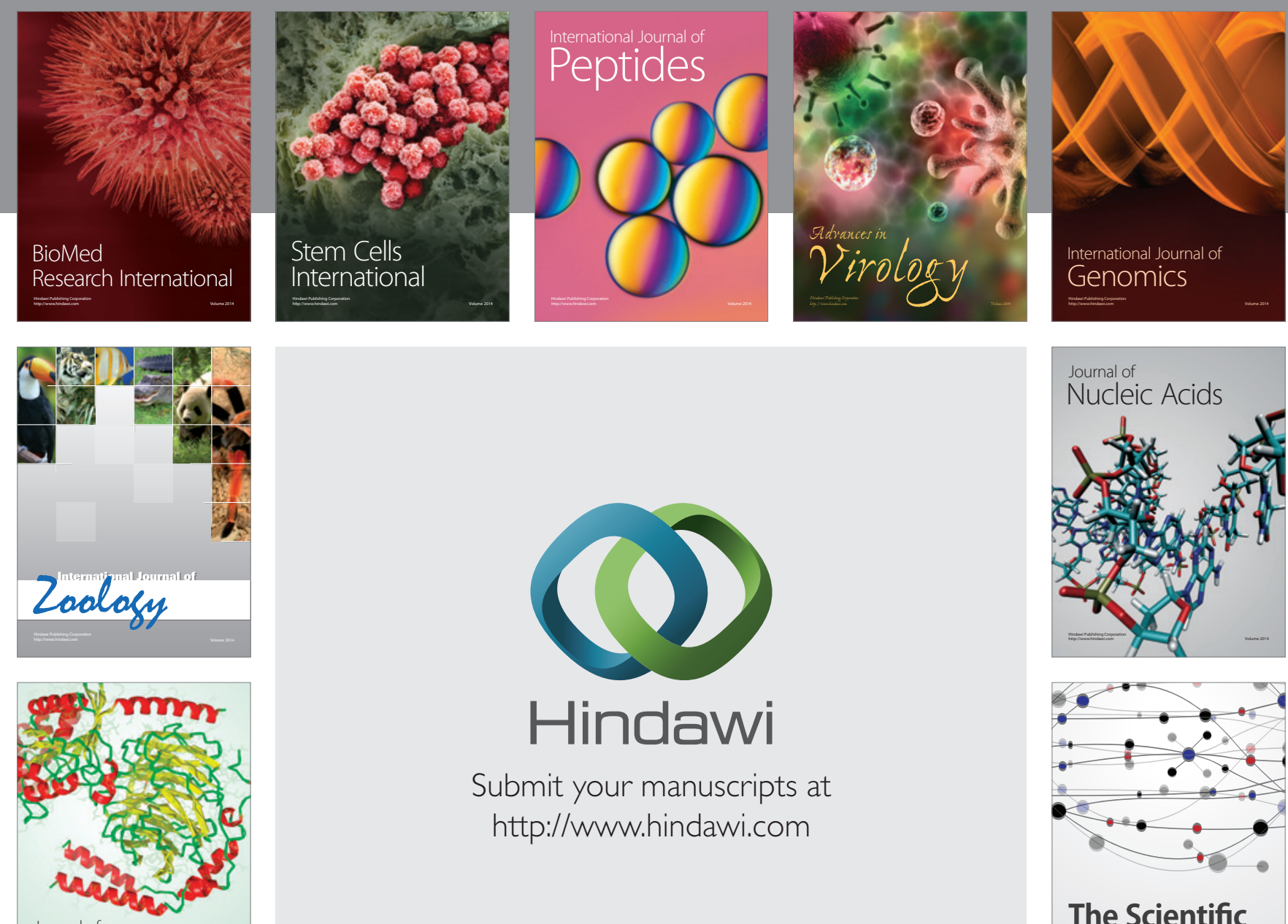

Submit your manuscripts at

http://www.hindawi.com

Journal of
Signal Transduction
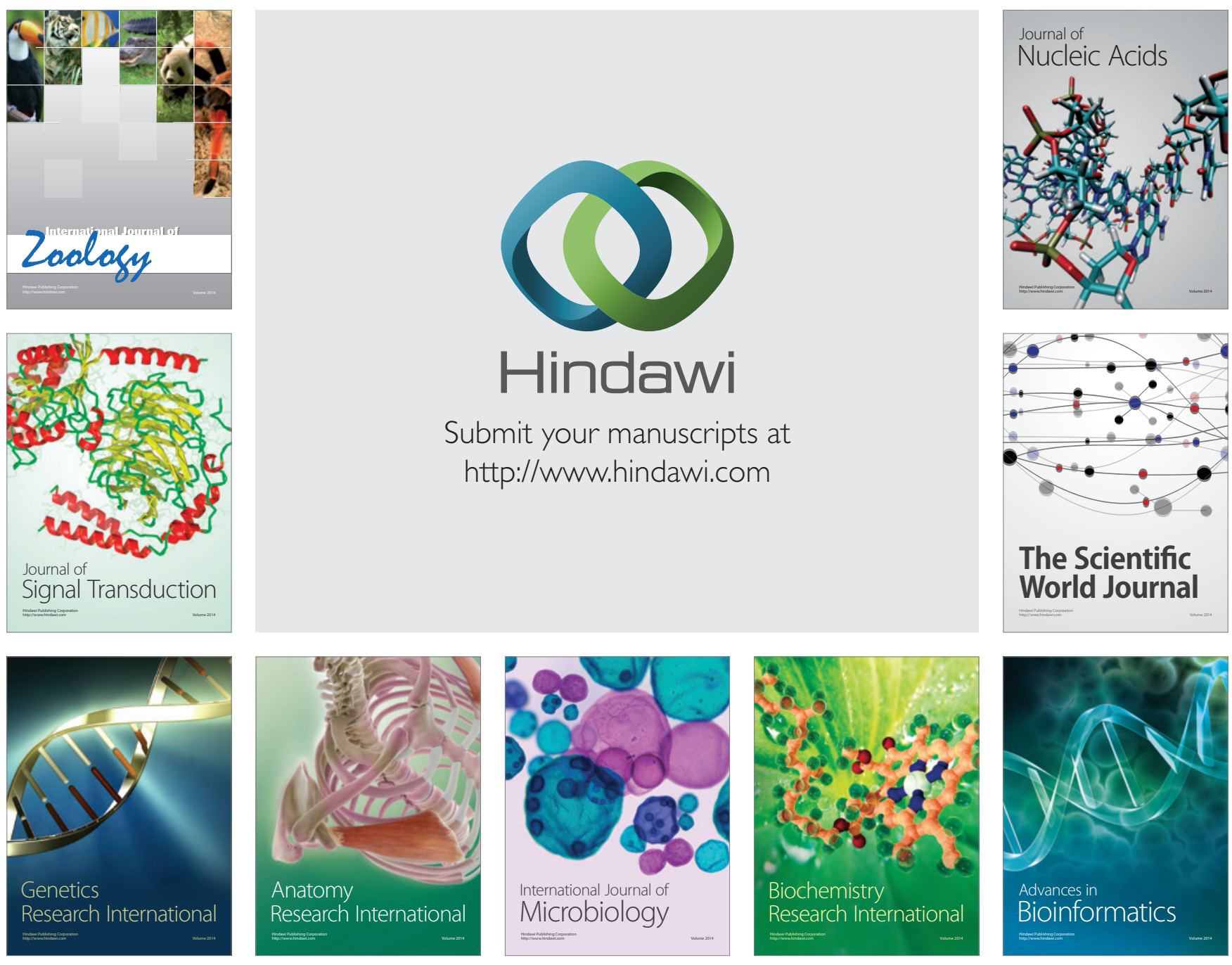

The Scientific World Journal
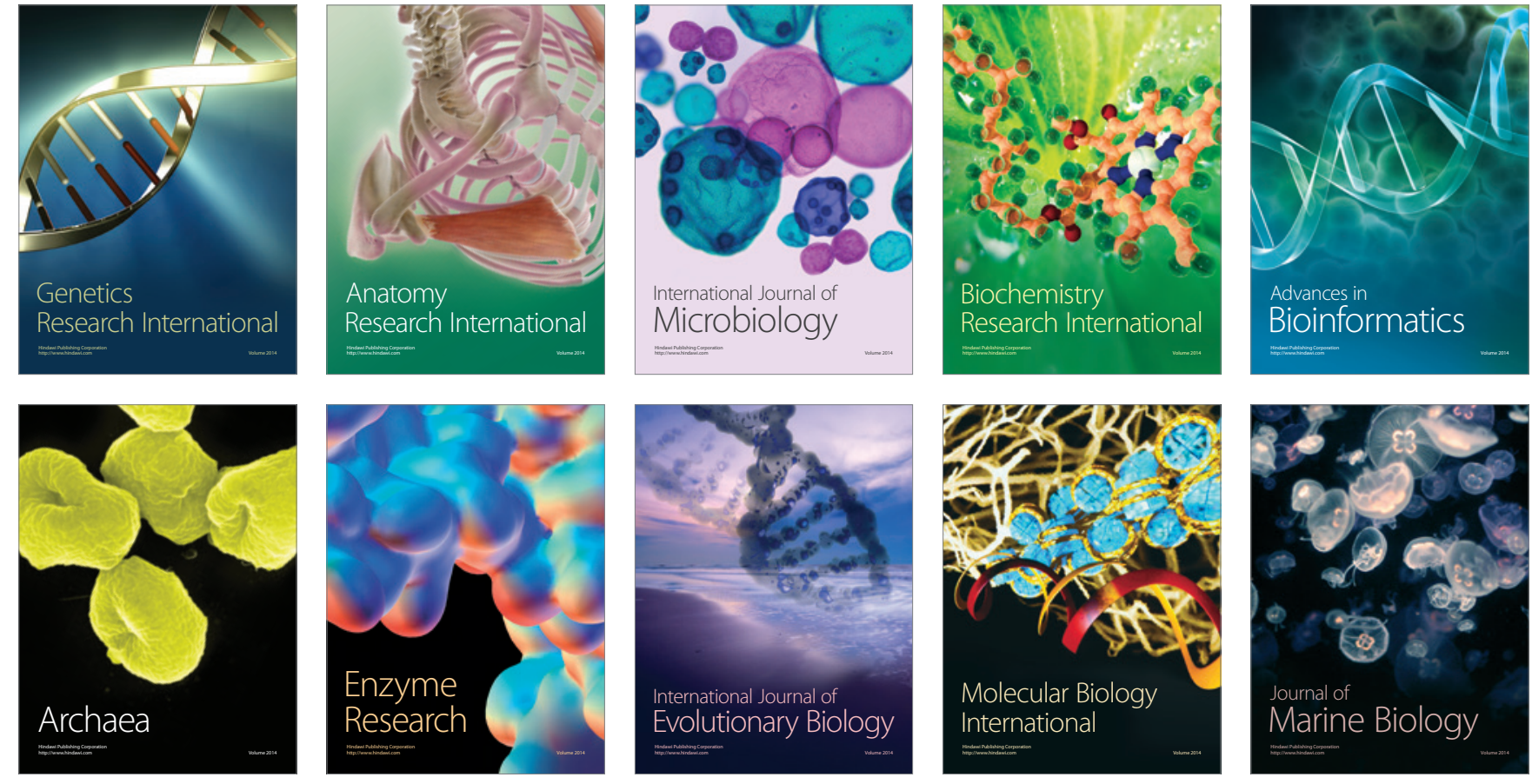